\title{
OPTİK FİBERLİ DAĞINIK ALGILAMANIN YÜKSEK GERİLİM KABLOLARINDAKİ KULLANIMINDA SICAKLIK VE GERGİNLIKK OLUŞUMLARININ YOUNG VE SHEAR MODÜLLERİ ÜZERİNDEKİ ETKİSí
}

\author{
Abdurrahman GÜNDAY*, Sait Eser KARLIK**, Güneş YILMAZ** \\ * Elektronik Teknolojisi Programı, Orhangazi Meslek Yüksek Okulu, Uludağ Üni., 16800, Orhangazi, Bursa \\ **Elektrik-Elektronik Mühendisliği Bölümü, Mühendislik Fakültesi, Uludağ Üni., 16059, Görükle, Bursa \\ agunday@uludag.edu.tr, ekarlik@uludag.edu.tr, gunesy@uludag.edu.tr
}

(Geliş/Received: 06.02.2013; Kabul/Accepted: 28.05.2014)

ÖZET

Bu çalışmada, XLPE yalıtkanlı yüksek gerilim (YG) kablolarında oluşan eşzamanlı sıcaklık ve gerginlik değişimlerinin algılanmasında kullanılabilecek yeni bir yöntem önerilmiştir. $\mathrm{Bu}$ yöntemde, Brillouin güç değişimlerinin sıcaklık bağımlılığını esas alan optik fiberli dağınık algılama prensibi ile algılayıcı fiberin Young modülü ve Shear modülünün, sıcaklık ve sıcaklık kaynaklı içsel gerginlik bağımlılı̆̆ından yararlanılmıştır. Çalışmada model olarak, Temmuz ayında Bursa bölgesinde $20^{\circ} \mathrm{C}$ ortam sıcaklığına sahip $1,5 \mathrm{~m}$ derinlikli kumlu toprak altına serilmiş, $2 \mathrm{~km}$ uzunluklu, $630 \mathrm{~mm}^{2}$ iletken kesitli, XLPE yalıtkanlı 89/154 kV YG kablosu esas alınmıştır. Algılayıcı fiber, $1550 \mathrm{~nm}$ 'de tek modlu optik fiberdir. Young modülü sıcaklık duyarlılığı YG kablosunun çalışma sıcaklığı bölgesinde $-2,33 \times 10^{-6} \% /{ }^{\circ} \mathrm{K}$ iken, Shear modülünde $-6,67 \times 10^{-7} \% /{ }^{\circ} \mathrm{K}$ şeklinde elde edilmiştir. Ayrıca, Young modülü gerginlik duyarlılığı ile Shear modülü gerginlik duyarlılığı, YG kablosu üzerindeki en sıcak noktada sırasıyla $\% 5,7154 \times 10^{-4}$ ve $\% 3,0502 \times 10^{-4}$ olarak bulunmuştur. Kablo çalışma rejiminde iken, sıcaklıktaki $1^{\circ} \mathrm{K}$ değişime karşılık kablo boyunca $\sim 26,83 \mu \varepsilon$ gerginlik değişimi meydana gelmiştir. Gerek teorik hesaplamalar gerekse benzetim sonuçları, Young modülü sıcaklık ve gerginlik duyarlılıklarından yararlanmanın, kablo çalışma süresi ve kapasitesi hakkında bilgi edinilmesi açısından Shear modülü sonuçlarına göre daha etkin bir yöntem olduğunu göstermektedir.

Anahtar Kelimeler: Young Modülü, Shear Modülü, Brillouin Saçılması, Optik Fiberli Dağınık Algılama, Sicaklık, Gerginlik, Yüksek Gerilim Kablosu.

\section{THE IMPACT OF TEMPERATURE AND STRAIN FORMATIONS ON YOUNG AND SHEAR MODULI IN USAGE OF OPTICAL FIBER DISTRIBUTED SENSING FOR POWER CABLES}

\begin{abstract}
In this study, a novel method that can be used for sensing temperature and strain changes simultaneously occurred along the XLPE insulated high voltage (HV) cables has been proposed. In this method, optical fiber distributed sensing principle based on the temperature dependence of Brillouin power changes and the temperature and intrinsic thermal strain dependencies of Young modulus and Shear modulus of the sensing fiber have been utilized. The cable model used in this study has been based on an XLPE insulated 89/154 kV power cable with a conductor cross-sectional area of $630 \mathrm{~mm}^{2}$ and a length of $2 \mathrm{~km}$, which has been laid under $1.5 \mathrm{~m}$ of a sandy ground of Bursa with an ambient temperature of $20^{\circ} \mathrm{C}$ in July. The sensing fiber is a single mode fiber at $1550 \mathrm{~nm}$. While temperature sensitivity of the Young modulus has been determined as $-2.33 \times 10^{-6} \% /{ }^{\circ} \mathrm{K}$ in the operation temperature region of the power cable, that of the Shear modulus has been obtained as $-6.67 \times 10^{-7} \% /{ }^{\circ} \mathrm{K}$. Furthermore, strain sensitivities of Young and Shear moduli at the hottest point of the power cable have been obtained as $5.7154 \times 10^{-4} \%$ and $3.0502 \times 10^{-4} \%$, respectively. In the operation regime of the cable, $\sim 26.83 \mu \varepsilon$ strain variation has been occurred for a $1{ }^{\circ} \mathrm{K}$ variation in the temperature along the cable. Both theoretical computations and simulation results show that it is a more efficient method to utilize
\end{abstract}


strain and temperature sensitivities of the Young modulus in gathering information about the lifespan and the capacity of the power cable with respect to thats of the Shear modulus.

Key Words: Young Modulus, Shear Modulus, Brillouin Scattering, Optical Fiber Distributed Sensing, Temperature, Strain, Power Cable

\section{GIRIŞ (INTRODUCTION)}

Genleşmesi kısıtlanmış bir malzemede sıcaklık değişimine bağlı olarak gerilmeler meydana gelebilir. $\mathrm{Bu}$ gerilmeler, ısıl genleşme katsayısı $\alpha$ ile orantılıdır. Sicaklık dT kadar arttırılırsa, l uzunluklu silindirik bir cismin boyundaki dl miktarındaki artış, $\mathrm{dl}=\alpha$. l. dT bağıntısı ile hesaplanabilir. Bir cisimde, isıl etkilerle meydana gelen birim uzamaveya şekil değiştirme elastik sınırlar içinde gerilmelerle doğru orantılıdır. Cisim üzerinde sıcaklık kaynaklı olarak meydana gelen isıl gerilmeler (1)'de verildiği gibi ifade edilmektedir [1].

$\sigma=\mathrm{E} . \epsilon=\mathrm{E} . \alpha \cdot \mathrm{dT}$

Eşitlikte, E malzemenin Young modülünü, $\sigma$ cisim üzerinde oluşan ısıl gerilmeyi (uzunlamasına gerilme) ve $\in$ ise 1 sıl gerginliği (birim uzamayı) ifade etmektedir. Cisim gerilmeye maruz kalırsa, atomlar arası uzaklık gerilme doğrultusunda artar, enine doğrultuda ise bağ kuvvetleri etkisinde azalır. Bu tür yer değiştirmelere atomlar arası bağlar karşı koyar ve cismin elastik şekil değiştirme özelliklerini belirler. Elastik şekil değiştirmenin ölçütü olarak değerlendirilen elastik şekil değiştirme direnci, elastisite modülü veya Young modülü olarak ifade edilmektedir. Bir başka ifade ile Young modülü, bir malzeme veya cismin elastik şekil değiştirmesinin ve orijinal şekline dönmesinin bir ölçüsü olarak tanımlanmaktadır. Young modülünün birimi $\mathrm{N} / \mathrm{m}^{2}$ veya GPa'dır ve bir cisim veya malzeme üzerindeki herhangi bir noktada meydan gelen gerilmeler ile gerginliklerin oranı olarak (2)'de verildiği gibi ifade edilebilmektedir [1,2].

$\mathrm{E}=\frac{\text { Gerilme }}{\text { Gerginlik }}=\frac{\mathrm{F} / \mathrm{A}}{\Delta \mathrm{L} / \mathrm{L}}=\frac{\sigma}{\epsilon}$

Eşitlikte; F uygulanan kuvveti, A kuvvetin uygulandığı alanı, $\Delta \mathrm{L}$ cismin kuvvet sonucu uzama miktarını ve L ise cismin ilk boyunu ifade etmektedir. Shear modülü veya kayma modülü, kayma gerilmesinin kayma gerginliğine (kayma şekil değiştirmesi) oranı olarak tanımlanır ve (3)'te verildiği gibi ifade edilmektedir. Birimi GPa'dır [1].

$\mathrm{G}=\frac{\mathrm{F} / \mathrm{A}}{\Delta \mathrm{x} / \mathrm{L}}=\frac{\tau}{\gamma}$

Eşitlikte; G Shear (kayma) modülünü, $\Delta \mathrm{x}$ enlemesine yer değiştirme (kayma) miktarını, $\tau$ kayma gerilmesini ve $\gamma$ kayma şekil değiştirmesini ifade etmektedir.
Bir malzemede Shear modülünden bahsedebilmek için, malzemenin kristal yapısı boyunca, kayma doğrultusundaki kayma gerilmesi bileşeninin, o kayma sisteminin kayma direncine eşit olması gerekmektedir. Bir cisim için kayma olayı, ancak atomlar arası bağ kuvvetlerini yenerek oluşabilmektedir. Farklı hızda soğuma sürecine sahip malzemeler için, sicaklık farkından dolayı 1sıl gerilmeler meydana gelebilir. Yüksek sıcaklıktaki bir malzeme parçası hızla soğutulursa, yüzeyi hemen soğur ve sertleşir, içi yumuşak ve sıcak kalır. İç kısmı zamanla soğurken büzülmeye çalışır, fakat sert dış kısım buna engel olur. Bunun sonucunda da, diş yüzeyde basınç gerilmeleri ve iç kısımda ise çekme gerilmeleri meydana gelir [1].

Özellikle XLPE yalıtkanlı bakır ve alüminyum iletkenli yüksek gerilim kabloları, çalışma esnasında kablodan geçen yük akımındaki değişimlere ve bu değişimlerden kaynaklanan yüksek sicaklık oluşumlarına maruz kalabilmektedir. XLPE yalıtkanlı YG kablolarında meydana gelen bu sicaklık oluşumları ile sıcaklık kaynaklı gerginlik değișimleri, özellikle kablo yalıtkanında yaşlanma sürecinin hızlanmasina neden olmaktadır. $\mathrm{Bu}$ durum, XLPE yalıtkanlı YG kablolarının yüksek maliyeti ile birleşince, kablo iletkeni ve yalıtkanında oluşan sıcaklığın ve sıcaklık kaynaklı içsel gerginliklerin tespit edilmesini önemli hale getirmektedir.

YG kablolarında gerek iletkenin, ekran tellerinin ve metal zirh malzemelerin gerekse, yalıtkan malzemelerin 1sıl etkilere bağlı olarak farklı hızlarda genleşmeve büzülme özelliği göstermesi, yalıtkan üzerinde boşlukların oluşmasına neden olabilmektedir. Söz konusu oluşumlar, dielektrik alan etkisi ile ortaya çıkan kısmi boşalmalar meydana getirerek, kablonun akım taşıma kapasitesini önemli ölçüde sınırlandırmaktadır [3]. Bu sınırlamalar, gerek 1sıl etkilerin gerekse sıcaklık kaynaklı gerginliklerin önceden tespit edilerek çözülmesini gerektirmektedir. Young modülünün ve Shear modülünün sicaklık ve gerginlik değişimlerinden doğrudan etkilenmesi, bu iki parametrenin optik fiberli algılamada kullanılarak, kablonun verimliliği ve çalışma süresi ile ilgili ortaya çıkabilecek sıcaklık ve gerginlik değişimi kaynaklı problemlerin önceden tespit edilip önlenmesi açısından önemli bir imkân sunmaktadır. Bunun yanı sıra, 1sıl etkilerin analizi ile malzemenin kırılganlığ ve sertliği ile ilgili doğru değerlendirmeler yapmak da mümkün olmaktadır.

$\mathrm{Bu}$ çalışmada, sadece bir foto alıcı ile kablo üzerindeki çok sayıda ölçüm noktasından fiziksel 
verinin alınabildiği bir yöntem olan optik fiberli dağınık algılama metodundan yararlanılmıştır. Optik fiberli dağınık algılama metodunda, fiberin kendisi algılama elemanı olarak kullanılabilmektedir [4]. Bu yönteme göre, fibere pompalanan işaretin Brillouin güç ifadesinden yararlanılarak kablo boyunca sıcaklık verileri elde edilmiş ve bu sicaklık değişimlerinin neden olduğu gerginlik oluşumları Young modülü kullanılarak tespit edilmiştir.

Literatürde Brillouin saçılma mekanizmasını temel alan optik fiberli algılayıcılarda, kullanılan lazerin ve optik fiberin çalışma dalgaboyuna bağlı olarak farklı dalgaboylarında giriş işaretlerinin kullanıldığ çalışmalar mevcuttur [5-10]. Ancak son yillardaki çalışmalarda ağırlıklı olarak $1550 \mathrm{~nm}$ dalgaboylu ışın vericilerin kullanıldığı algılayıcılar önerilmektedir [11-17]. Bunun en önemli nedeni, günümüzde dağınık algılayıcıların kilometreler mertebesinde algılama mesafesine sahip uygulamalarda kullanılması ve dolayısıyla işaret zayıflamasının büyük önem arz etmesidir. $1550 \mathrm{~nm}$ bölgesinde standart haberleşme fiberinin kullanıldığı uygulamalarda zayıflama minimum olmaktadır. $\mathrm{Bu}$ noktadan hareketle, çalışmada sunulan modelde kablonun $2 \mathrm{~km}$ uzunluklu olması nedeniyle, zayıflamanın etkisini minimize ederek algılayıcının performansını yüksek tutmak amaçlanmış velazerden fibere pompalanan işaretin dalga boyu $1550 \mathrm{~nm}$ seçilmiştir. Dolayısıyla, algılamanın da $1550 \mathrm{~nm}$ civarındaki Brillouin Stokes ve Brillouin anti-Stokes bileșenlerinden yararlanılarak gerçekleştirildiği kabul edilmiştir.

\section{YOUNG MODÜLÜNÜN SICAKLIK VE GERGINLİK BAĞIMLILIĞI (STRAIN AND TEMPERATURE DEPENDENCES OF THE YOUNG} MODULUS)

Silika camlar için Young modülü, (4)'te verildiği gibi sıcaklıkla doğrusal olarak değişmektedir [18].

$\mathrm{E}_{(\mathrm{T})}=69,68+1,126 \times 10^{-2} \mathrm{~T} \quad[\mathrm{GPa}]$

Eşitlikte; $\mathrm{T},{ }^{\circ} \mathrm{K} \quad$ cinsinden sıcaklığa karşılık gelmektedir.

Young modülünün sıcaklıkla yüzdesel değişimi veya sicaklık duyarlılığı (5)'te elde edilmiştir.

$\frac{1}{E_{(T)}} \frac{\mathrm{dE}_{(\mathrm{T})}}{\mathrm{dT}}=\frac{1}{6188,28+\mathrm{T}}$

Görüldüğü gibi, Young modülünün sicaklık duyarlılığı, sıcaklıkla ters orantılı biçimde değişim göstermekte olup $293^{\circ} \mathrm{K}$ ortam sicaklığı için $\% 15,429 \times 10^{-3}$ değerini almaktadır.

Young modülü, gerginlikle doğrusal olarak değişmektedir [18]. Bu ilişki (6)'da verilmiştir.
$\mathrm{E}_{\epsilon}=\mathrm{E}_{\mathrm{o}}(1+5,75 \in)$

(6)' $\mathrm{daE}_{\mathrm{o}}=72,98 \mathrm{GPa}$ sifir gerginlik ve $293{ }^{\circ} \mathrm{K}$ sıcaklıktaki Young modülüne, $\in$ ise gerginliğe karşılık gelmektedir [18].

Young modülünün gerginlikle yüzdesel değişimi veya gerginlik duyarlılı̆̆ (7)'de verildiği gibi elde edilmiştir. Kablo üzerinde gerginliğin maksimum olduğu bölgede gerginlik duyarlılığı en küçük değerini almaktadır.

$\frac{1}{\mathrm{E}_{(\epsilon)}} \frac{\mathrm{dE}_{(\epsilon)}}{\mathrm{d} \epsilon}=\frac{1}{0,174+\epsilon}$

(4) ve (6) kullanılarak $\mathrm{T}>293{ }^{\circ} \mathrm{K}$ değerlerindeki algılayıcı optik fiber sıcaklığı için, kablo üzerinde sıcaklık değişiminin neden olduğu Young modülü değişimi (8)'de verildiği gibi elde edilebilmektedir. Eşitlikte $\mathrm{T}(\mathrm{z})$, kablo boyunca sıcaklık değişimine karşılık gelmektedir.

$\Delta \mathrm{E}_{(\mathrm{T})}=\mathrm{E}_{(\mathrm{T})}-\mathrm{E}_{0}=1,126 \times 10^{-2} \times \mathrm{T}(\mathrm{z})-3,3 \mathrm{GPa}$

$\mathrm{E}_{\mathrm{o}}$ referans alınarak, kablonun çalışması esnasında meydana gelen sıcaklık değişimlerinin neden olduğu gerginlik oluşumları, (8)' in (6)'da yerine konması ile (9)'da verildiği gibi elde edilebilmektedir.

$\epsilon=\frac{E_{(T)}-E_{0}}{E_{0} \times 5,75}=26,83 T-7864$

Eşitlikte, $\mathrm{T}{ }^{\circ} \mathrm{K}$ cinsinden sıcaklığ $1, \epsilon$ ise $\mu \epsilon$ cinsinden sıcaklık kaynaklı içsel gerginliği ifade etmektedir. Görüldüğü gibi, algılayıc1 optik fiber boyunca meydana gelen gerginlik oluşumları ile sıcaklık oluşumları arasında doğrusal bir bağıntı bulunmaktadır.

Sıcaklık ile gerginlik arasındaki ilişki Şekil 1'de verilmiştir. Algılayıcı optik fiberde, $320{ }^{\circ} \mathrm{K}-332{ }^{\circ} \mathrm{K}$ aralığındaki sıcaklık değişimine karşılık, $722 \mu \epsilon-1044 \mu \epsilon$ aralığında gerginlik değişimi elde edilmişstir.

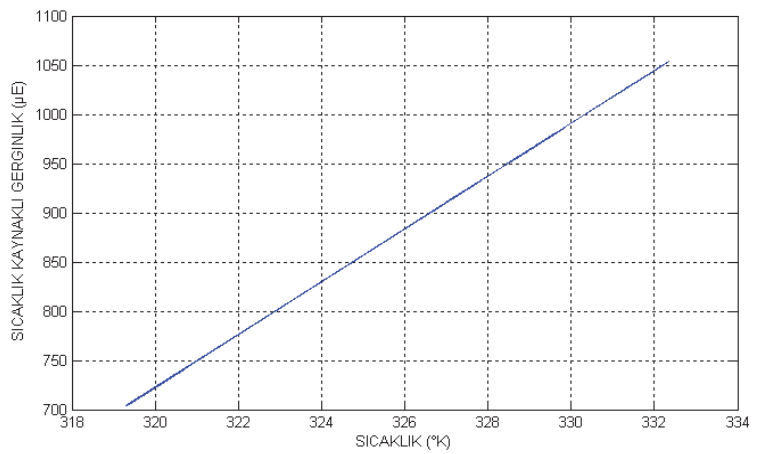

Şekil 1. Algılayıcı optik fiber boyunca $320^{\circ} \mathrm{K}-332{ }^{\circ} \mathrm{K}$ aralığındaki sıcaklık değişimine karşılık gerginlik değişimi (Strain variation vs. temperature variation in the range of $320^{\circ} \mathrm{K}-332{ }^{\circ} \mathrm{K}$ along the sensing optical fiber) 
3. SHEAR MODÜLÜNÜN SICAKLIK VE GERGINLIK BAĞIMLILIĞI (STRAIN AND TEMPERATURE DEPENDENCES OF THE SHEAR MODULUS)

Shear modülü değeri ne kadar büyükse, malzemenin sertliği veya esnemezliğio kadar yüksek olmakta ve kırılganlığı artmaktadır. Bazı malzemelerin $293{ }^{\circ} \mathrm{K}$ sıcaklığındaki tipik malzeme özellikleri Tablo 1'de verilmiştir [1, 3, 19, 20].

Shear modülü, kablo üzerinde meydana gelen gerginlik değişimlerinin fonksiyonu olarak (10)'da verildiği gibi ifade edilebilmektedir. Eşitlikte; $\mathrm{G}_{0}=32,1 \mathrm{GPa}$ olarak verilmektedir [18].

$\mathrm{G}_{(\epsilon)}=\mathrm{G}_{0}(1+3,06 \epsilon)$

Modülün gerginlikle yüzdesel değişimi (gerginlik duyarlılı̆̆ı) (11)'de elde edilmiştir.

$\frac{1}{\mathrm{G}_{(\epsilon)}} \frac{\mathrm{dG}_{(\epsilon)}}{\mathrm{d} \epsilon}=\frac{1}{0,327+\epsilon}$

Shear modülünün gerginlik duyarlılığı, kablo boyunca gerginlikle doğrusal olarak azalmaktadır.

(9) eşitliği, (10)'da yerine yazılarak Shear modülünün sıcaklıkla değişimi, (12)'de verildiği gibi ifade edilebilmektedir.

$\mathrm{G}_{(\mathrm{T})}=31,328+2,636 \times 10^{-3} \mathrm{~T} \quad[\mathrm{GPa}]$

Shear modülünün sicaklıkla yüzdesel değişimi veya sıcaklık duyarlılığı (13)’te elde edilmiştir.

$\frac{1}{G_{(T)}} \frac{\mathrm{dG}_{(\mathrm{T})}}{\mathrm{dT}}=\frac{1}{11884,67+\mathrm{T}}$

Shear modülünün sıcaklık duyarlılığı, $293^{\circ} \mathrm{K}$ ortam sıcaklığı için \% 8,212 x 10 $0^{-3}$ değerini almaktadır.

\section{BENZETIMLER (SIMULATIONS)}

Brillouin güç değişimi esasına dayalı dağınık sıcaklık ve gerginlik algılamada, Temmuz ayı içinde Bursa bölgesinde ortalama $20{ }^{\circ} \mathrm{C}$ ortam sicaklığına sahip kumlu özellikteki $1,5 \mathrm{~m}$ derinlikli toprak altına serilmiş, $2 \mathrm{~km}$ uzunluklu, $630 \mathrm{~mm}^{2}$ iletken kesitli, XLPE yalıtkanlı 89/154 kV YG kablosu model olarak seçilmiştir. Kablo boyunca Young modülü ve Shear modülü değişimleri için aşağıdaki koşullar baz alınmıştır:

Model olarak seçilen YG kablosu,

- $300 \mathrm{~m}$ - $400 \mathrm{~m}$ arasinda ve $700 \mathrm{~m}$ - $735 \mathrm{~m}$ arasında, sırasiyla $100 \mathrm{~m}$ ve $35 \mathrm{~m}$ uzunluğundaki $145 \mathrm{~mm} \times 5 \mathrm{~mm}$ ebatlı PVC borular içerisinden geçirilmektedir.

- $1200 \mathrm{~m}$ - $1320 \mathrm{~m}$ arasında $155 \mathrm{~mm}$ x 5 mm ebatlı bir PVC boru içerisinden geçirilmesine ilaveten, $1240 \mathrm{~m} \mathrm{-} 1280 \mathrm{~m}$ aralığında $180 \mathrm{~mm} \mathrm{x} 7 \mathrm{~mm}$ ebatlı ısıl geçirgenliği daha düşük ikinci bir PVC boru içerisinden de geçirilmektedir.

- 1700. metrede ise başka bir YG kablosu ile kesişmekte ve 2000. metrede dağıtım noktasına ulaşmaktadır.

- Herhangi bir harici gerginliğe maruz kalmamaktadır.

Benzetimlerde kullanılan algılayıcı fibere ait parametreler aşağıda verilmiştir:

- Optik fiber kablo uzunluğu: $\mathrm{L}=2000 \mathrm{~m}$.

- Lazerin pompaladığı işaretin maksimum gücü: $\mathrm{P}_{0}=2,2 \mathrm{~W}$.

- Pompalanan işaretin dalga boyu: $\lambda_{0}=1550 \mathrm{~nm}$.

- Pompalanan işaretin darbe süresi: $\tau=20$ ns.

- Optik fiberin çekirdek kırılma indisi: $\mathrm{n}_{1}=1,50$.

- Optik fiberin kılıf kırılma indisi: $\mathrm{n}_{2}=1,48$.

- Optik fiber yakalama katsayısı: $\mathrm{S}=0,0066$.

- Işı̆̆ın boşluktaki hızı: $\mathrm{c}=3 \times 10^{8} \mathrm{~m} / \mathrm{s}$.

- Uzamsal çözünürlük: $\mathrm{l}=\mathrm{c} \tau / 2 \mathrm{n}_{1}=2 \mathrm{~m}$.

- Dağınık sıcaklık algılamada ölçüm alınan nokta say1s1: $\mathrm{R}=\mathrm{L} / \mathrm{l}=1000$ nokta.

- Brillouin güç değişiminin sicaklık katsayısı: $\mathrm{K}_{\mathrm{T}}^{\mathrm{P}}=0,36 \pm 0,030 \% /{ }^{\circ} \mathrm{K}[21,22]$.

- Işı̆̆ı fiber içerisinde ilerleme hızı: $\mathrm{v}_{\mathrm{g}}=\mathrm{c} / \mathrm{n}_{1}=2 \times 10^{8} \mathrm{~m} / \mathrm{s}$.

- Optik fiberin içerisinde meydana gelen akustik dalga hizı: $\mathrm{v}_{\mathrm{a}}=5960 \mathrm{~m} / \mathrm{s}$.

- Foto elastik (Pockel) katsayı: $\mathrm{p}=0,286$.

- Silika fiberin yoğunluğu: $\rho=2330 \mathrm{~kg} / \mathrm{m}^{3}$.

- Optik fiberin fiktif (denge) sıcaklığı: $\mathrm{T}_{\mathrm{f}}=1950^{\circ} \mathrm{K}[18]$.

Tablo 1. Bazı malzemelerin $293^{\circ} \mathrm{K}$ sıcaklığındaki tipik malzeme özellikleri (Typical material properties of various materials at $293^{\circ} \mathrm{K}$ temperature)

\begin{tabular}{|c|c|c|c|c|c|}
\hline Malzeme & $\begin{array}{c}\text { Elastisite } \\
\text { Modülü (E) } \\
\mathbf{( G P a )}\end{array}$ & $\begin{array}{c}\text { Kayma } \\
\text { Modülü (G) } \\
\mathbf{( G P a )}\end{array}$ & $\begin{array}{c}\text { Poisson } \\
\text { Oranı }\end{array}$ & $\begin{array}{c}\text { Isıl Genleşme } \\
\text { Katsayısı } \\
\left({ }^{\circ} \mathbf{K}\right)^{-1}\end{array}$ & $\begin{array}{c}\text { Elektriksel } \\
\text { Illetkenlik } \\
(\mathbf{\Omega m})^{-1}\end{array}$ \\
\hline Silika Fiber & 72,98 & 32,10 & 0,165 & $5,0 \times 10^{-7}$ & $1,0 \times 10^{-18}$ \\
\hline Cam & 70 & 29,43 & 0,22 & $9,0 \times 10^{-6}$ & $1,0 \times 10^{-12}$ \\
\hline XLPE yalıtkan & 0,50 & 0,18 & 0,37 & $150 \times 10^{-6}$ & $1,0 \times 10^{-15}$ \\
\hline Bakır & 115 & 42,5 & 0,35 & $16,2 \times 10^{-6}$ & $5,85 \times 10^{7}$ \\
\hline Alüminyum & 70 & 26 & 0,34 & $23,8 \times 10^{-6}$ & $2,95 \times 10^{7}$ \\
\hline
\end{tabular}


- Fiktif sicaklıkta silika fiberin izotermal sıkıştırılabilirlik katsayısı: $\beta_{\mathrm{T}}=7 \times 10^{-11} \mathrm{~m}^{2} / \mathrm{N}$ [18].

- İletken ile algilayıcı optik fiber arasındaki sıcaklık farkı için sıcaklık düzeltme faktörü: $\Delta \mathrm{T}=32^{\circ} \mathrm{C}$.

Model olarak seçilen optik fiber entegre edilmiş 89/154 kV YG kablosunun fotoğrafı Şekil 2'de verilmiştir.

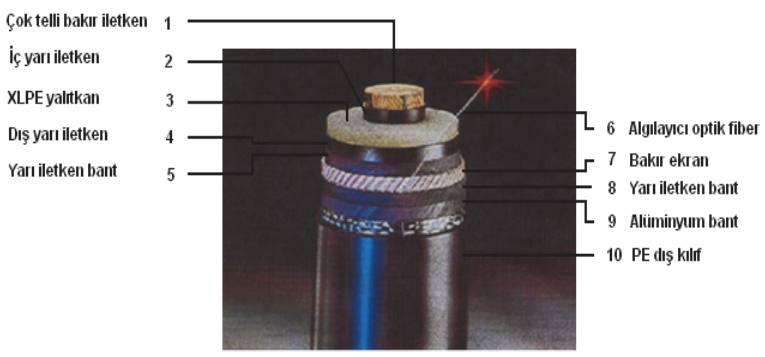

Şekil 2. Optik fiber entegre edilmiş 89/154 kV YG kablosu (An optical fiber integrated $89 / 154 \mathrm{kV}$ power cable)

Algılayıcı fiber boyunca geriye saçılan işaretin Brillouin gücü değişimi $\mathrm{P}_{\mathrm{B}}$, (14) ile elde edilir [21].

$\mathrm{P}_{\mathrm{B}}(\mathrm{z})=0,5 \mathrm{P}_{0} \tau \alpha_{\mathrm{B}} \mathrm{Sv}_{\mathrm{g}} \mathrm{e}^{\left(-2 \alpha_{\mathrm{R}} \mathrm{z}\right)}$

Eşitlikte; $\mathrm{P}_{0}$ lazerin pompaladığı işaretin maksimum gücünü, $\tau$ pompalanan işaretin darbe süresini, $\alpha_{R}$ ve $\alpha_{B}$ sirasıyla Rayleigh ve Brillouin saçılma katsayılarını, $\mathrm{S}$ yakalama katsayısını, $\mathrm{v}_{\mathrm{g}}$ fiberde ilerleyen 1şı̆̆ın grup hızını ve $\mathrm{z}$ mesafeyi ifade etmektedir. $\alpha_{\mathrm{R}}$ ve $\alpha_{\mathrm{B}}$ katsayıları (15) ile tanımlanabilir [18].

$\alpha_{\mathrm{R}}=\left(8 \pi^{3} \mathrm{n}^{8} \mathrm{p}^{2} \mathrm{kT}_{\mathrm{f}}\left[\beta_{\mathrm{T}}-\left(\rho v_{\mathrm{a}}^{2}\right)^{-1}\right]\right) / 3 \lambda_{0}^{4}$

$\alpha_{\mathrm{B}}=\left(8 \pi^{3} \mathrm{n}^{8} \mathrm{p}^{2} \mathrm{kT}\left(\rho \mathrm{v}_{\mathrm{a}}^{2}\right)^{-1}\right) / 3 \lambda_{0}^{4}$

Eşitlikte; $\mathrm{n}$ fiberin çekirdek kırılma indisini, p Pockel katsayısını, $\mathrm{k} \quad$ Boltzman sabitini $\left(\mathrm{k}=1,38 \times 10^{-23} \mathrm{~J} /{ }^{\circ} \mathrm{K}\right), \quad \mathrm{T}{ }^{\circ} \mathrm{K}$ cinsinden fiberin sıcaklığını, $\mathrm{T}_{\mathrm{f}}{ }^{\circ} \mathrm{K}$ cinsinden fiberin fiktif sıcaklığını, $\beta_{\mathrm{T}}$ fiktif sicaklıkta silika fiberin izotermal sıkıştırılabilirlik katsayısını, $\rho$ silika fiberin yoğunluğunu, $v_{\mathrm{a}}$ akustik dalga hızını ve $\lambda_{0}$ fiber içerisine pompalanan 1şı̆̆ın dalga boyunu ifade etmektedir.

Brillouin saçılma mekanizmasını kullanan dağınık sıcaklık algılamada (DTS), kablo boyunca meydana gelen sicaklık bilgileri, Brillouin güç değişiminin sıcaklık bağımlılığı ifadesinden elde edilebilmektedir [22-24].

Brillouin güç değişiminin sıcaklık ve gerginlik bağımlılığı (16) ile verilmektedir [21-23].

$\Delta \mathrm{P}_{\mathrm{B}}=\mathrm{K}_{\mathrm{T}}^{\mathrm{P}} \Delta \mathrm{T}+\mathrm{K}_{\epsilon}^{\mathrm{P}} \Delta \epsilon$
Eşitlikte; $\mathrm{K}_{\mathrm{T}}^{\mathrm{P}}$ Brillouin güç değişiminin sıcaklık katsayısını, $\mathrm{K}_{\epsilon}^{\mathrm{P}}$ Brillouin güç değişiminin gerginlik katsayısını, $\Delta$ Tve $\Delta \in$ sirasiyla, algılayıcı fiber boyunca meydana gelen sıcaklık ve içsel gerginlik değişimlerini ifade etmektedir.

$320{ }^{\circ} \mathrm{K}-332{ }^{\circ} \mathrm{K}$ aralığında, algılayıcı optik fiberde geriye saçılan işaretin Brillouin gücündeki değişim üzerinde sıcaklığın etkisi \%93 seviyelerinde iken, sıcaklık kaynaklı içsel gerginlik oluşumlarının etkisi $\sim 7$ seviyelerindedir. $\mathrm{Bu}$ nedenle, Brillouin gücü üzerindeki sıcaklık kaynaklı içsel gerginliklerin etkisi ihmal edilebilmektedir. Dolayısıyla, bu çalışmada, YG kablosu boyunca algılayıc1 optik fiberdeki sıcaklıkdeğişimi verileri, (16) kullanılarak ve eşitlikteki $\mathrm{K}_{\in}^{\mathrm{P}} \Delta \in$ katkısı ihmal edilerek elde edilmiştir.

YG kablosu boyunca algılayıcı optik fiberin sıcaklık profili Şekil 3'te verilmiştir.

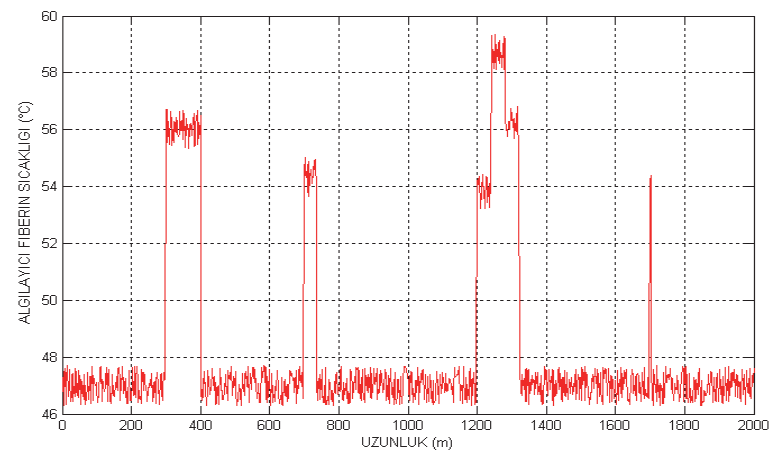

Şekil 3. YG kablosu boyunca algılayıcı optik fiberin sicaklık profili (Temperature profile of the sensing optical fiber along the power cable)

Optik fiberin sicaklığ $1,47{ }^{\circ} \mathrm{C}-59{ }^{\circ} \mathrm{C}\left(320{ }^{\circ} \mathrm{K}-332{ }^{\circ} \mathrm{K}\right)$ aralığında değişim göstermektedir. En yüksek sıcaklık değerine, YG kablosunun 180 mmx7 mm ebatlı PVC bir boru içerisinden geçirildiği bölgede $59,34{ }^{\circ} \mathrm{C}$ ile ulaşılmıştır.

YG kablosunun bakır iletkeni ile ekran telleri arasındaki manyetik olmayan metal tüpler içerisine yerleştirilmiş algılayıcı optik fiber arasında $30^{\circ} \mathrm{C}-35^{\circ} \mathrm{C}$ sicaklık farkı bulunmaktadır. $\mathrm{Bu}$ fark, genelde iletken, XLPE yalıtkan ve koruyucu kılıf malzemelerinin 1sıl geçirgenlik katsayılarına, kablonun içinden geçtiği PVC borunun ve boru ile kablo arasındaki havanın 1sıl transfer özelliklerine, kablonun serildiği toprağın nemlilik derecesine ve isıl geçirgenliğine, diş ortamın mevsimsel sicaklık değişimlerine bağlıdır [25, 26]. Şekil 4'te görülen, YG kablosu boyunca kablo iletkeninin sicaklık profili benzetiminde, sıcaklık farkı (model alınan kablo için $32{ }^{\circ} \mathrm{C}$ ) sıcaklık düzeltme faktörü olarak algılayıcı fiberin sıcaklık değerine eklenmiştir.

Sicaklık artışının maksimum olduğu bölgeler, ortalama $88^{\circ} \mathrm{C}$ ile YG kablosunun $100 \mathrm{~m}$ uzunluklu PVC boru içerisinden geçirildiği $300 \mathrm{~m}-400 \mathrm{~m}$ arası ve ortalama $90,6{ }^{\circ} \mathrm{C}$ ile YG kablosunun 1sıl geçirgenliği 
daha düşük olan ikinci bir PVC boru içerisinden geçirildiği $1240 \mathrm{~m}-1280 \mathrm{~m}$ aralığıdır. $300 \mathrm{~m}-400 \mathrm{~m}$ aralığındaki en sıcak nokta $88,72{ }^{\circ} \mathrm{C}$ ile 300 . metre iken, kablo üzerinde tespit edilen en sicak nokta 91,34 ${ }^{\circ} \mathrm{C}$ sicaklık değeri ile 1250. metredir. YG kablosunun, $700 \mathrm{~m}-735 \mathrm{~m}$ arasında $35 \mathrm{~m}$ uzunluklu PVC boru içerisinden geçirildiği bölgede ve 1700. metrede başka bir YG kablosu ile kesiştiği noktada, sicaklik sirasiyla, $86,9{ }^{\circ} \mathrm{C}$ ve $86,4{ }^{\circ} \mathrm{C}$ değerlerine ulaşmıştır.

XLPE yalıtkanlı YG kablolarında maksimum çalışma sıcaklığı olan $90{ }^{\circ} \mathrm{C}$ değeri, Şekil 4'teki profilden de görüldüğü üzere sadece bir bölgede geçilmiştir.

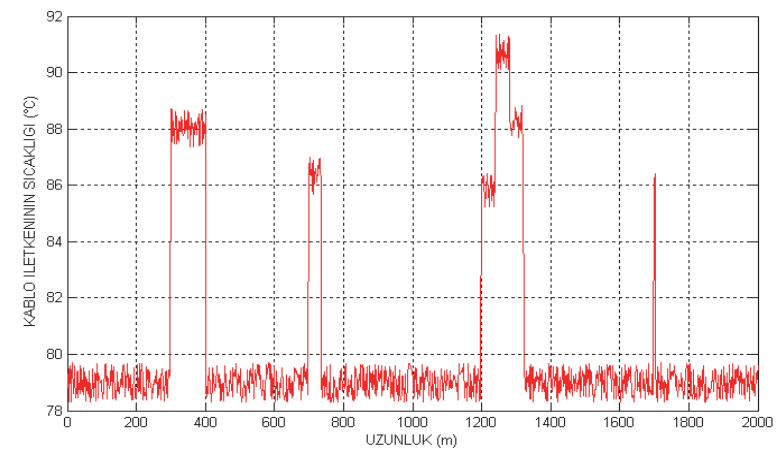

Şekil 4. YG kablosu boyunca kablo iletkeninin sicaklık profili (Temperature profile of the cable conductor along the power cable)

Kablo üzerinde tespit edilen sıcak noktaların doğrusal bir fonksiyonu olarak Young modülü değişimi Şekil 5'teki gibi elde edilmiştir. Young modülü, maksimum çalışma sicaklığının aşıldığ 240 m-1280 m bölgesinde 73,42 GPa ile maksimum değerine ulaşmıştır.

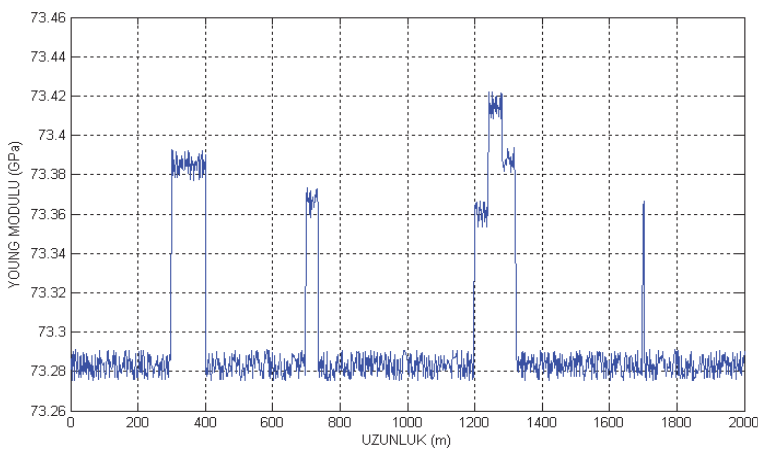

Şekil 5. Algılayıcı optik fiber boyunca sıcaklık nedeni ile meydana gelen Young modülü değişimi (Variation of the Young modulus caused by the temperature along the sensing optical fiber)

Şekil 6'da Young modülünün sıcaklık bağımlılığı ve sıcaklık duyarlılığı (sıcaklıkla yüzdesel değişimi) verilmiştir. Young modülü, sıcaklığın maksimum olduğu noktada en yüksek değerine ulaşırken, bu noktada sıcaklık duyarlılığı minimum değerine erişmiştir. Young modülü sıcaklık duyarlılığı, $320^{\circ} \mathrm{K}$, $326^{\circ} \mathrm{K}$ ve $332{ }^{\circ} \mathrm{K}$ için sirasıyla, \% $15,365 \times 10^{-3}$, $\% 15,351 \times 10^{-3}$ ve $\% 15,337 \times 10^{-3}$ değerlerini almıştır. YG kablosunun çalışma rejiminde (algılayııı optik fiberin $320^{\circ} \mathrm{K}-332^{\circ} \mathrm{K}$ sicaklık aralığında), Young modülünün sicaklıkla değişimi $1,126 \times 10^{-2} \mathrm{GPa} /{ }^{\circ} \mathrm{K}$ ve sicaklık duyarlılığ $-2,33 \times 10^{-6} \% /{ }^{\circ} \mathrm{K}$ değerlerini almaktadır.

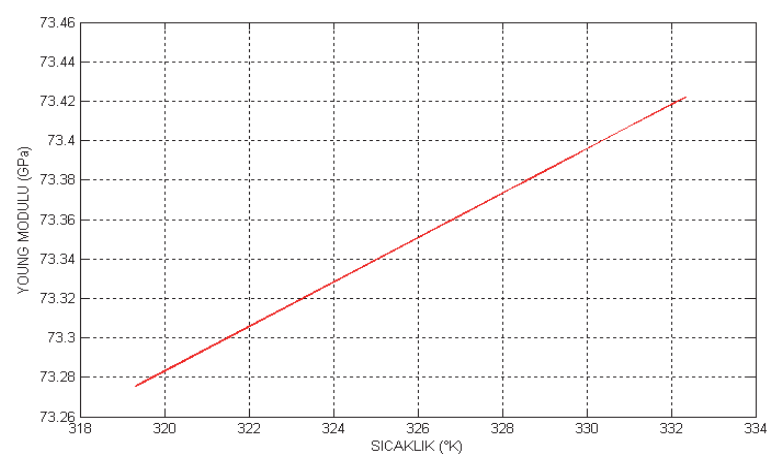

(a)

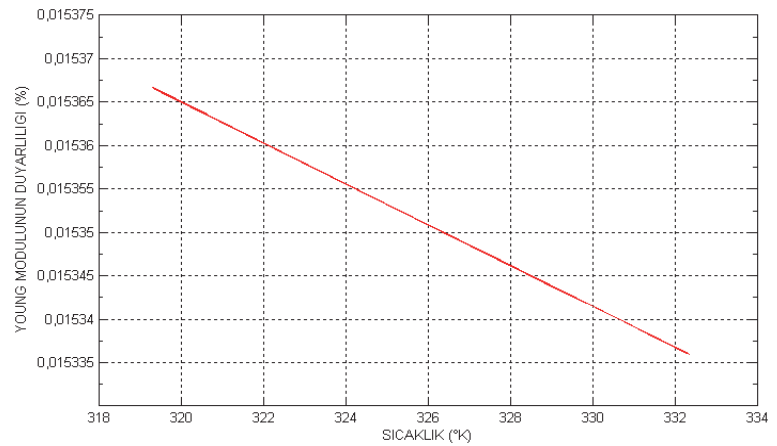

(b)

Şekil 6. a) Young modülünün sıcaklıkla değişimi (Variation of the Young modulus with temperature) ve b) Young modülünün sıcaklık duyarlılığı (sıcaklıkla yüzdesel değișimi) (temperature sensitivity of the Young modulus, i.e. percentile variation with temperature)

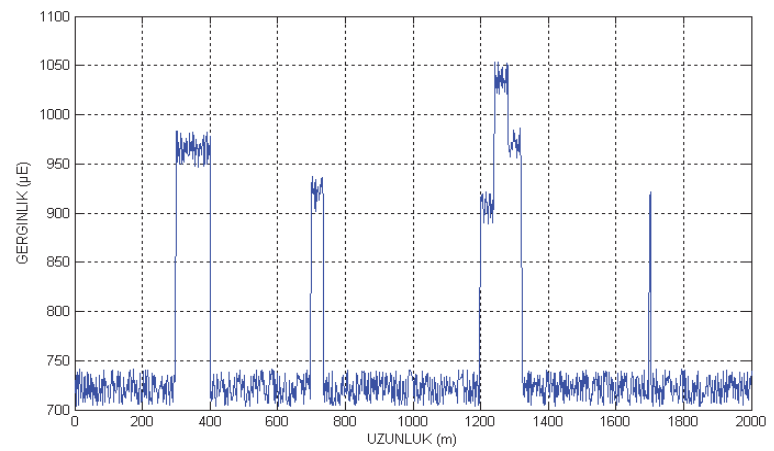

Şekil 7. Algılayıcı optik fiber boyunca sıcaklık kaynaklı gerginlik oluşumları (293 ${ }^{\circ} \mathrm{K}$ sıcaklık referans alınmıştır) (Thermal strain formations along the sensing optical fiber) (The reference temperature is $293^{\circ} \mathrm{K}$ )

Şekil 7'de sıcaklığa bağlı olarak ortaya çıkan gerginlik oluşumlarının $2 \mathrm{~km}$ uzunluklu kablo boyunca değişimi gösterilmiştir. Gerginlik maksimum değerine $1054 \mu \varepsilon$ ile $1240 \mathrm{~m}-1280 \mathrm{~m}$ arasında, YG kablosunun, $180 \mathrm{mmx} 7 \mathrm{~mm}$ ebatlı PVC boru içerisinden geçirildiği bölgede ulaşmıştır. İki YG kablosunun kesiştiği 1700. metrede ise, sicaklık kaynaklı gerginlik değeri $921 \mu \varepsilon$ olmuştur. 
Young modülünün, YG kablosu boyunca meydana gelen ve optik fiber ile algılanan gerginlik oluşumlarına bağımlılı̆̆ Şekil 8'de verilen Young modülünün gerginlikle değişimi grafiğinden de görülmektedir.

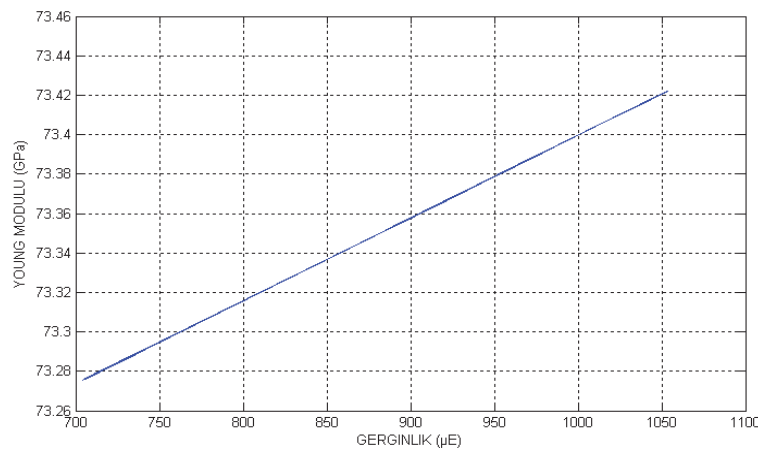

Şekil 8. Young modülünün gerginlikle değişimi (Variation of the Young modulus with strain)

Şekil 8'den anlaşılacağı üzere, Young modülündeki $1 \mathrm{GPa}$ değişim için $2382 \mu \varepsilon$ büyüklüğünde gerginlik değişimi gerekir. Diğer bir ifade ile Young modülünün gerginlikle değişimi $4,20 \times 10^{-4} \mathrm{GPa} / \mu \varepsilon$ şeklindedir.

$2 \mathrm{~km}$ uzunluklu YG kablosu boyunca Shear modülünün değişimi ve Shear modülünün gerginlikle olan ilişkisi Şekil 9'da gösterilmiştir.

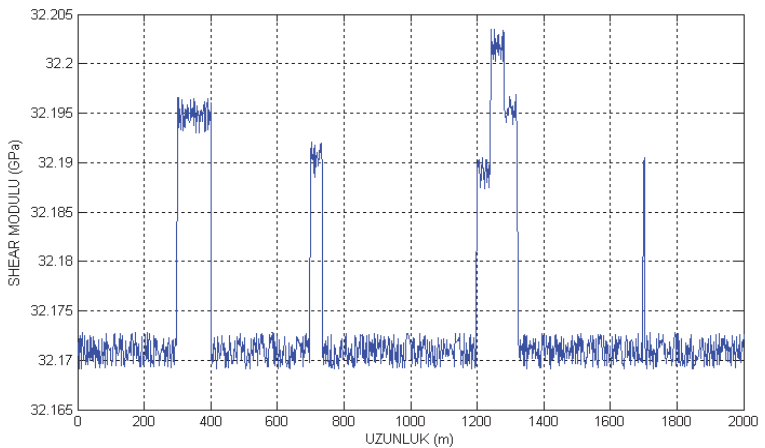

(a)

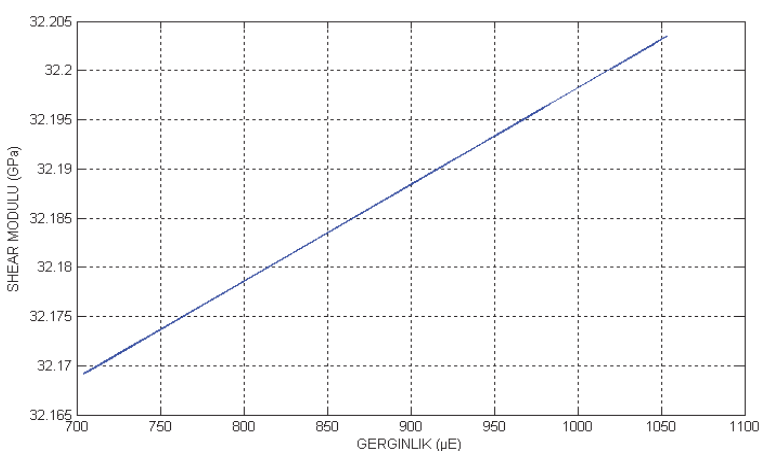

(b)

Şekil 9. a) Shear modülünün YG kablosu boyunca değişimi (Variation of the Shear modulus along the power cable) ve b) Shear modülünün gerginlikle değişimi (Variation of the Shear modulus with strain)
Shear modülü, gerginliğe doğrusal olarak bağlıdır. Maksimum değerini, 32,203 GPa ile 1250. metrede almıştır. Bu noktada gerginlik, $1054 \mu \varepsilon$ ile en yüksek değerine ulaşmıştır. Şekil 9(b)'den, Shear modülünün gerginlikle değişiminin $9,82 \times 10^{-5} \mathrm{GPa} / \mu \varepsilon$ şeklinde olduğu görülmektedir.

Shear modülünün sicaklıkla değişimi ve sıcaklık duyarlılığı (sıcaklıkla yüzdesel değişimi) Şekil 10'da gösterilmiştir. Shear modülünün sıcaklık duyarlılığı, sıcaklık artışı ile doğrusal olarak azalmaktadır. Shear modülü sicaklık duyarlılığ $1,320{ }^{\circ} \mathrm{K}, 326{ }^{\circ} \mathrm{K}$ ve $332{ }^{\circ} \mathrm{K}$ sıcaklıkları için, sırasıyla, \% 8,193 $\times 10^{-3}$, $\% 8,189 \times 10^{-3}$ ve $\% 8,185 \times 10^{-3}$ değerlerini almıştır. Şekil 10'daki veriler kullanılarak, Shear modülünün sıcaklıkla değişimi $2,636 \times 10^{-3} \mathrm{GPa} /{ }^{\circ} \mathrm{K}$ ve sicaklık duyarlılığ 1 ise $-6,67 \times 10^{-7} \% /{ }^{\circ} \mathrm{K}$ olarak hesaplanmıştır.

Young modülünün ve Shear modülünün gerginlik duyarlılıkları Şekil 11'de verilmiştir. Young modülü ve Shear modülünün gerginlik duyarlılıkları, algılayıcı optik fiberin gerginlik değişimi aralığında

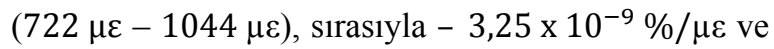
$-9,35 \times 10^{-10} \% / \mu \varepsilon$ olarak elde edilmiştir. YG kablosunun $90{ }^{\circ} \mathrm{C}$ maksimum çalışma sıcaklığının aşıldığı bölgede, duyarlılıklar sirasıyla $\% 5,7154 \times 10^{-4}$ ve $\% 3,0502 \times 10^{-4}$ değerlerini almiştır.

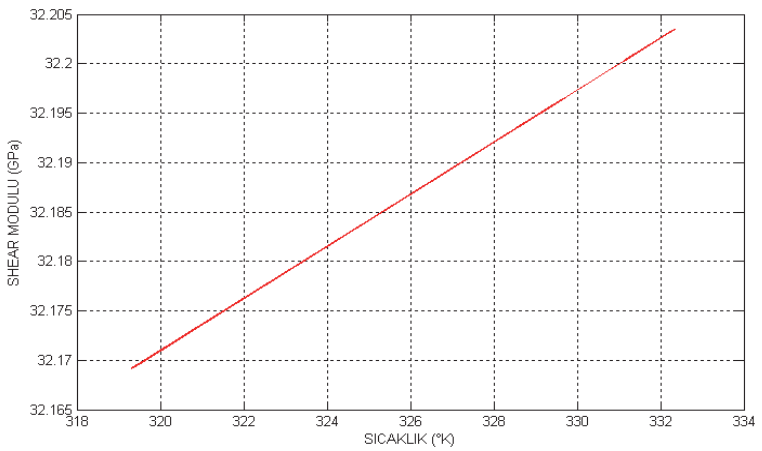

(a)

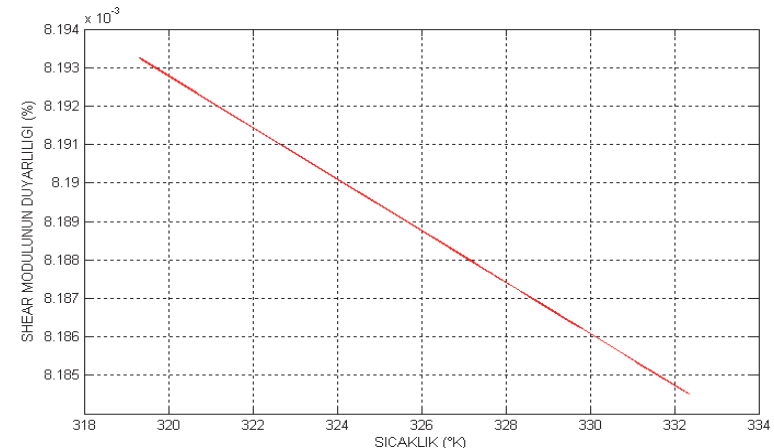

(b)

Şekil 10. a) Shear modülünün sıcaklıkla değişimi (Variation of the Shear modulus with temperature) ve b) Shear modülünün sıcaklık duyarlılığı (sıcaklıkla yüzdesel değişimi) (temperature sensitivity of the Shear modulus, i.e. percentile variation with temperature) 


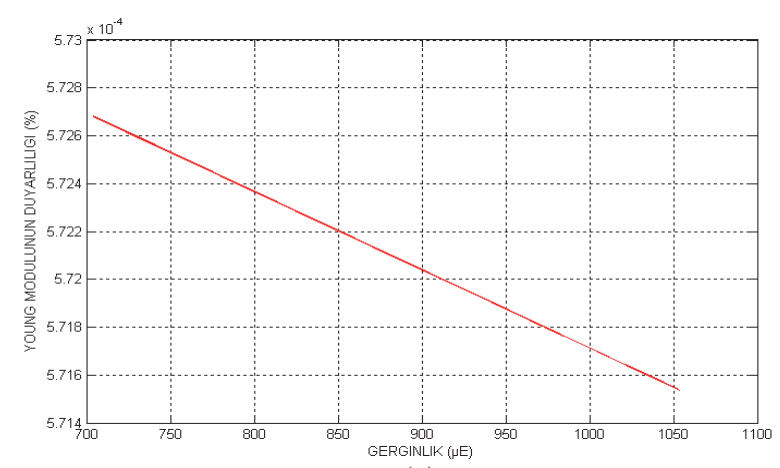

(a)

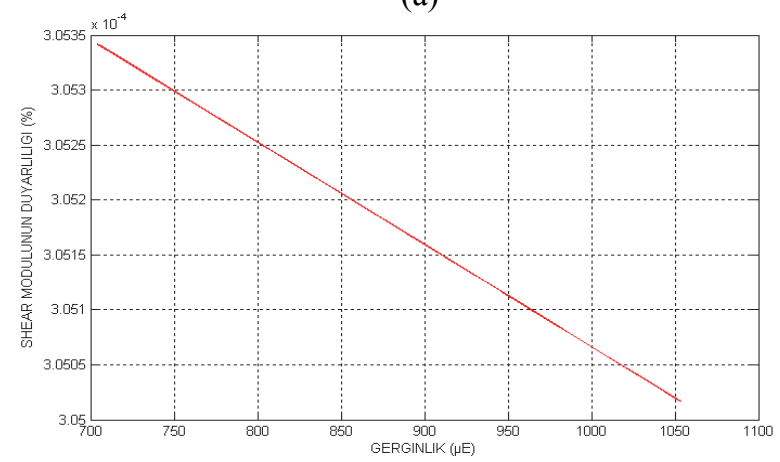

(b)

Şekil 11. a) Young modülünün gerginlik duyarlılığ (gerginlikle yüzdesel değişimi) (strain sensitivity of the Young modulus, i.e. percentile variation with strain) ve b) Shear modülünün gerginlik duyarlılığı (gerginlikle yüzdesel değişimi) (strain sensitivity of the Shear modulus, i.e. percentile variation with strain)

\section{SONUÇ (CONCLUSION)}

$\mathrm{Bu}$ çalışmada, Brillouin güç değişimini esas alan dağınık algılama metodundan yararlanılarak, XLPE yalıtkanlı 89/154 kV YG kablosunda meydana gelen sıcaklık oluşumları ile ısıl etkiler neticesinde ortaya çıkan içsel gerginlikler incelenmiştir. Algılayıcı fiber boyunca meydana gelen sicaklık değişimlerinin ve buna bağlı içsel gerginlik oluşumlarının belirlenebilmesi için, silika fiberin Young modülü değişimlerinden yararlanılmış ve fiber boyunca sıcaklık ve içsel gerginlik profilleri elde edilmiştir. Bunun yanı sıra, algılayıcı fiberin sertliğini ve kırılganlığını saptamak açısından önemli olan Shear modülünün de sıcaklık ve içsel gerginlik algılamada kullanılabilirliğini incelemek amacıyla benzetimler yapılmıştır.

Elde edilen sonuçlar, algılayıcı optik fiberin $320^{\circ} \mathrm{K}-332{ }^{\circ} \mathrm{K}$ çalışma sıcaklığı aralığında, Young modülü sıcaklık duyarlılığının $\left(-2,33 \times 10^{-6} \% /{ }^{\circ} \mathrm{K}\right)$, Shear modülü sicaklık duyarlılığından $\left(-6,67 \times 10^{-7} \% /{ }^{\circ} \mathrm{K}\right)$ yaklaşık olarak 3,5 kat daha büyük olduğunu göstermiştir. Bununla birlikte, Young modülü gerginlik duyarlılığının $-3,25 \times 10^{-9} \% / \mu \varepsilon$ ve Shear modülü gerginlik duyarlılığının ise $-9,35 \times 10^{-10} \% / \mu \varepsilon$ seviyelerinde olduğu tespit edilmiştir.
Uzun mesafeli yeraltı enerji nakil hatlarında, dağınık optik fiberli sensörlerle sıcaklığın ve gerginliğin eş zamanlı algılanmasında, gerek Young modülünden gerekse Shear modülünden yararlanılabilir. Young ve Shear modüllerindeki değişimlerin eşzamanlı sıcaklık ve gerginlik izlemede kullanımı, sıcaklık ve gerginliğin XLPE yalıtkanlı YG kablolarında zamanla ortaya çıkaracağı fiziksel deformasyonun, elektriksel kayıpların ve termo-mekanik etkilerin tespiti ve önlenmesinde faydalanılabilecek önemli bir yöntem olacaktır.

\section{KAYNAKLAR (REFERENCES)}

1. Onaran, K., Malzeme Bilimi, Bilim Teknik Yayınevi, 11. Baskı, İstanbul, 2009.

2. Sokkar, T.Z.N., Shams El-Din, M.A. ve El-Tawargy, A.S., “On Young's Modulus Profile Across Anisotropic Nonhomogeneous Polymeric Fibre Using Automatic Transverse Interferometric Method", Optics and Lasers in Engineering,50 (9):1223-1229, 2012.

3. Heinhold, L., "Power Cables", Power Cables and Their Application, 3rd Edition,Part 1, Editor: Heinhold, L., Siemens Aktiengesellschaft, Berlin, Germany, 134-139, 1990.

4. Yilmaz, G., Karlık, S.E., “A Distributed Optical Fiber Sensor for Temperature Detection in Power Cables", Sensors and Actuators A:Physical, 125 (2): 148-155, 2006.

5. Culverhouse, D., Farahi, F., Pannell, C.N. ve Jackson, D.A., "Potential of Stimulated Brillouin Scattering as Sensing Mechanism for Distributed Temperature Sensors", Electronics Letters, 25 (14): 913-914, 1989.

6. Ghogomu, N.N. ve Everard, J.K.A., "Coherent Photoconductive Detection of Brillouin Scattering for Temperature Sensing", Electronics Letters, 31 (18): 1606-1607, 1995.

7. Bao, X., Dhliwayo, J., Heron, N., Webb, D.J. ve Jackson, D.A., "Experimental and Theoretical Studies on a Distributed Temperature Sensor Based on Brillouin Scattering", Journal of Lightwave Technology, 13 (7): 1340-1348, 1995.

8. Davis, M.A. ve Kersey, A.D., "Simultaneous Measurement of Temperature and Strain Using Fibre Bragg Gratings and Brillouin Scattering", IEE Proceedings - Optoelectronics, 144 (3): 151-155, 1997.

9. Lecoeuche, V., Hathaway, M.W., Webb, D.J., Pannell, C.N. ve Jackson, D.A., " $20-\mathrm{km}$ Distributed Temperature Sensor Based on Spontaneous Brillouin Scattering", IEEE Photonics Technology Letters, 12 (10): 1367-1369, 2000.

10. Parker, T.R., Farhadiroushan, M., Feced, R., Handerek, V.A. ve Rogers, A.J., "Simultaneous Distributed Measurement of Strain and Temperature from Noise-Initiated Brillouin 
Scattering in Optical Fibers", IEEE Journal of Quantum Electronics, 34 (4): 645-659, 1998.

11. Bernini, R., Minardo, A., Persiano, G.V., Vaccaro, A., Villacci, D. ve Zeni, L., "Dynamic Loading of Overhead Lines by Adaptive Learning Techniques and Distributed Temperature Sensing”, IET Generation, Transmission \& Distribution, 1 (6): 912-919, 2007.

12. Diaz, S., Mafang, S.F., Lopez-Amo, M. ve Thevenaz, L., "A High-Performance Optical Time-Domain Brillouin Distributed Fiber Sensor", IEEE Sensors Journal, 8 (7): 12681272, 2008.

13. Soto, M.A., Bolognini, G., Di Pasquale, F., "Enhanced Simultaneous Distributed Strain and Temperature Fiber Sensor Employing Spontaneous Brillouin Scattering and Optical Pulse Coding", IEEE Photonics Technology Letters, 21 (7): 450-452, 2009.

14. Zou, W., He, Z. ve Hotate, K., "Demonstration of Brillouin Distributed Discrimination of Strain and Temperature Using a PolarizationMaintaining Optical Fiber", IEEE Photonics Technology Letters, 22 (8): 526-528, 2010.

15. Wang, L. ve Shu, C., "Demonstration of Distributed Strain Sensing with the Use of Stimulated Brillouin Scattering-Based Slow Light", IEEE Photonics Journal, 3 (6): 1164-1170, 2011.

16. Angulo-Vinuesa, X., Martin-Lopez, S., Nuno, J., Corredera, P., Ania-Castanon, J.D., Thevenaz, L. ve Gonzalez-Herraez, M., "Raman-Assisted Brillouin Distributed Temperature Sensor Over $100 \mathrm{~km}$ Featuring $2 \mathrm{~m}$ Resolution and $1.2^{\circ} \mathrm{C}$ Uncertainty", Journal of Lightwave Technology, 30 (8): 1060-1065, 2012.

17. Luo, J., Hao, Y., Ye, Q., Hao, Y. ve Li, L., "Development of Optical Fiber Sensors Based on Brillouin Scattering and FBG for On-Line Monitoring in Overhead Transmission Lines", Journal of Lightwave Technology, 31 (10): 1559-1565, 2013.

18. De Souza, K.R.C.P., Fiber Optic Distributed Sensing Based on Spontaneous Brillouin Scattering, $\mathrm{PhD}$ Dissertation, University of Southampton, 1999.
19. Wang, W.H., "The Elastic Properties, Elastic Models and Elastic Perspectives of Metallic Glasses", Progress in Materials Science, 57 (3): 487-656, 2012.

20. Lu, Y., Li, C., Zhang, $X$. ve Yam, S., "Determination of Thermal Residual Strain in Cabled Optical Fiber with High Spatial Resolution by Brillouin Optical Time-Domain Reflectometry", Optics and Lasers in Engineering, 49 (9-10): 1111-1117, 2011.

21. Alahbabi, M., Distributed Optical Fiber Sensors Based on the Coherent Detection of Spontaneous Brillouin Scattering, $\mathrm{PhD}$ Dissertation, University of Southampton, 2005.

22. Shang-hui, X., Li, L., "Signal Processing on Brillouin Scattering Based Distributed Fibre Sensors", Symposium on Photonics and Optoelectronics SOPO 2009, Wuhan, China, 14, 14-16 August 2009.

23. Günday, A., Yılmaz, G. ve Karlık, S.E., "Optik Fiberli Dağınık Algılama Yöntemiyle Enerji Kablosunda Sicaklı ve Gerginliğin Algılanması", Uludağ Üniversitesi Mühendislik-Mimarlık Fakültesi Dergisi, 12 (2): 43-52, 2007.

24. Günday, A., Yılmaz, G. ve Karlı, S.E., "Spontaneous Raman Power and Brillouin Frequency Shift Method Based Distributed Temperature and Strain Detection in Power Cables", 5th International Conference on Electrical and Electronics Engineering ELECO 2007, Bursa, Turkey, 326-330, 5-9 December 2007.

25. Aras, F., Oysu, C., "Thermal Analysis of $154 \mathrm{kV}$ Underground Cable Joint Using Finite Element Method", Journal of the Faculty of Engineering and Architecture of Gazi University, 22 (3): 281-286, 2007.

26. Ichino, T., Suzuki, T., Wada, T. ve Sadahiro, T., "Measurement of Conductor Temperature of Power Cable by Optical Fiber Sensor", 7th International Conference on Dielectric Materials Measurements \& Applications, University of Bath, UK., 303-306, 23-26 September 1996. 
